\title{
RELAÇÖES DE PODERES (INTER)PROFISSIONAIS E (INTER)INSTITUCIONAIS NO HOSPITAL
}

\author{
INTERPROFESSIONAL AND INTERINSTITUTIONAL POWER \\ RELATIONSHIPS IN A HOSPITAL \\ LAS RELACIONES DE PODER (INTER)PROFESIONALES E \\ (INTER)INSTITUCIONALES EN EL HOSPITAL
}

Beatriz Rosana Gonçalves de Oliveira'

Neusa Collet ${ }^{2}$

\begin{abstract}
RESUMO: Este estudo tem por objetivo fazer uma reflexão critica a respeito das relaçöes de poderes que permeiam as açōes profissionais e/ou institucionais no cotidiano do ambiente hospitalar. tomando por base uma situação concreta vivenciada por um grupo de enfermeiros docentes de uma universidade pública estadual do interior do Estado do Paraná que desencadeou um processo conflituoso nas relaçōes de poderes (inter)profissionais e (inter)institucionais. Reflete acerca da relação de poder no ambiente hospitalar destacando as inter-relaçōes que caracterizam a prática de enfermagem. Acreditamos que estas relações só podem ser compreendidas, refletidas e (re)construídas no cotidiano das açōes buscando um "novo" agir coletivo.
\end{abstract}

PALAVRAS-CHAVE: poder, relações (inter)profissionais e (inter)institucionais

\section{INTRODUÇÃO}

No modelo clínico de assistência ora vigente no sistema de saúde, especialmente nas organizações hospitalares, a produção de serviços efetiva-se no constante conflito e negociação entre os diversos poderes e saberes que o compöem. Por ser um trabalho profissional no qual médicos e enfermeiros controlam a produção de cuidados, sendo assegurado àqueles o ato médico propriamente dito, e a estes a administração da terapêutica e a constante informação sobre o cotidiano do doente, o trabalho médico e de enfermagem caracterizam-se pela oposição comando/execução na organização da divisão do trabalho.

Os médicos, vistos como legitimos representantes da saúde, buscam exercer o poder institucional e o controle do processo de trabalho, ficando os enfermeiros com a incumbêmcia de desenvolver parte do trabalho, que tem como resultado final a ação terapêutica sobre a doença. Em nossa experiência profissional, temos observado quotidianamente que o modelo de racionalidade do poder administrativo adotado nos serviços hospitalares está estruturalmente dominado pelo modelo da racionalidade médica, o que resulta num campo permeado de conflitos e negociaçōes entre os diferentes poderes e saberes, tendo, estrategicamente, as formas do poder médico como nucleares na lógica da produção e reprodução dessas instituições.

Assim, o hospital é um locus privilegiado para analisar a transformação das relações de

' Enfermeira, docente do Departamento de Enfermagem da Universidade Estadual do Oeste do Paraná - UNIOESTE, da disciplina Enfermagem Materno-Infantil II, Especialista em Enfermagem do Trabalho, e em Saúde Pública, mestranda em Enfermagem Fundamental na EERP-USP.

${ }^{2}$ Enfermeira, docente do Departamento de Enfermagem da Universidade Estadual do Oeste do Paraná - UNIOESTE, da disciplina Enfermagem Materno-Infantil II, Doutoranda em Enfermagem na EERP-USP. 
trabalho e o processo de imposição da medicina como a verdadeira ciência da saúde, (Pires, 1989). A compreensão das determinações histórico-sociais do poder nessa instituição possibilitanos intervir como agentes sociais na sua definição, ao invés de executar passivamente as resoluções advindas de cima para baixo.

Este estudo tem por objetivo fazer uma reflexão crítica a respeito das relações de poderes que permeiam as ações profissionais e/ou institucionais no cotidiano do ambiente hospitalar, tomando por base uma situação concreta vivenciada por um grupo de enfermeiros docentes de uma universidade pública estadual do interior do Estado do Paraná que desencadeou um processo conflituoso nas relações de poderes (inter)profissionais e (inter)institucionais.

\section{O EXERCÍCIO DO PODER: RELATO DE UMA SITUAÇÃO}

A disciplina estágio supervisionado em enfermagem materno infantil II tem suas atividades desenvolvidas em duas unidades de internação, a saber, unidade de berçário patológico e unidade de internação de clínica pediátrica. Este estágio é realizado com alunos da $4^{\mathrm{a}}$ série, portanto, formandos, cuja carga horária são 90 horas-aula, sendo distribuídas 30 e 60 horas-aula de atividades, respectivamente, prática esta que vinha sendo realizada há quatro anos. Em 1996, a instituição hospitalar onde são realizados estes estágios - hospital público (estadual) do município através de convênios desta instituição com a universidade, em função da inexistência de um hospital universitário - pleiteou o credenciamento de seu berçário patológico junto ao Sistema Único de Saúde como unidade de terapia intensiva neonatal, modificando sua prática em função disto.

Neste mesmo ano, as atividades de estágio foram iniciadas nas unidades no mês de abril, respeitando o convênio firmado e o cronograma estabelecido pela universidade e aceito pelo hospital. Os dois primeiros grupos de alunos desenvolveram seus estágios sem maiores problemas. Ao serem realizadas as atividades com o terceiro grupo, no mês de julho, foi concluída a etapa da unidade clínica e passamos para o berçário patológico. O primeiro dia de estágio transcorreu normalmente.

Entretanto, no segundo dia, as médicas plantonistas (a médica do turno da manhã estava passando o plantão para a médica do turno da tarde) questionaram sobre a realização do estágio naquela unidade (quem havia permitido? Qual autoridade havia permitido? Porque não haviam sido consultadas?) e nos colocaram seu desagrado com nossa presença de forma nada gentil, tendo nos "convidado" a nos retirar do campo de estágio. Apesar da estranheza causada por este fato, juntamente com a enfermeira responsável pela unidade, a docente dirigiu-se à enfermeira chefe da instituição para relatar o caso e perguntar qual a conduta a ser tomada em tal situação.

Com o convênio firmado entre a universidade e o hospital em mãos, a enfermeira chefe nos orientou a retornar à unidade e continuar a realizar o estágio normalmente, pois a mesma tomaria as devidas providências com a direção clínica (a quem o serviço de enfermagem é subordinado). Retornando à unidade, novamente foram (re)iniciadas as atividades do segundo dia de estágio. Às dezesseis horas desse mesmo dia, houve nova troca de plantão médico. A plantonista que assumiu as atividades após esse horário (a terceira médica envolvida, portanto), avisou a docente que, se não se retirasse imediatamente da unidade, iria abandonar o plantão e procurar a direção geral da instituição hospitalar, pois os médicos plantonistas não queriam estagiários naquele setor. Reforçou, ainda, que qualquer ocorrência com os bebês internados enquanto ela permanecesse ausente, seria de inteira responsabilidade da professora de estágio, uma vez que era ela com seus alunos que a estavam obrigando a se ausentar do cuidado aos seus pacientes. Com tantas atribulações para um único dia de estágio a professora, juntamente com seus alunos, optou pelo encerramento das atividades naquele dia e transferiu o problema para uma esfera maior de resolução, ou seja, envolveu o departamento de enfermagem da 
universidade e suas instâncias superiores.

Este fato atingiu espaços relacionados à ética de alunos e professores, expondo e determinando as ações de outros profissionais, na medida em que as formas de poder que acompanham os profissionais médicos medeia a análise da posição dominante da autoridade $\mathrm{e}$ responsabilidade, na produção das relações sociais, em que as fronteiras exigem constantes processos de negociação.

\section{O PODER MÉDICO: NUCLEAR NA PRODUÇÃO E REPRODUÇÃO DOS SERVIÇOS HOSPITALARES}

O saber e a competência técnica de cada profissional outorgam-Ihe um poder correspondente. O médico, na produção e reprodução dos serviços hospitalares no modelo clínico vigente, ocupa o poder nuclear na medida em que ele é o profissional que institui o processo de diagnóstico e terapêutica. Todos os outros profissionais e seus saberes: bioquimico, fisioterapêuta, nutricionista, enfermeiro, psicólogo, fonoaudiólogo e outros, entram em cena a partir de um indicativo médico. É este quem desencadeia todo o processo de restabelecimento da saúde ao corpo biológico doente.

Em relação ao trabalho exercido pelos profissionais de saúde, a atividade médica possui a máxima autonomia e exerce grande poder institucional. Os profissionais de enfermagem realizam as coordenações com as áreas de apoio e viabilizam o cumprimento de normas e rotinas nos serviços, situação que pode gerar conflitos inter-grupais. Estes intercâmbios de poder dificultam, na maioria das vezes, a convivência, a tolerância e o exercício da democracia (Agudelo, 1995).

Em uma investigação a respeito dos poderes e saberes nos hospitais Carapinheiro (1993) faz a seguinte afirmação:

\footnotetext{
"Como plataforma de mediação entre médicos e doentes, exige-se aos enfermeiros que desenvolvam não só um trabalho técnico, mas tambèm um trabalho de controlo social sobre os doentes, na manutençăo da ordem e da disciplina concebida pela autoridade social dos médicos. Na resposta a estas duas dimensöes das suas atividades, estabelecem-se entre médicos e enfermeiros situaçōes de tensão padronizada, podendo ser ou não acompanhadas de especificos processos de negociação. Relativamente ao que o médico considera que os enfermeiros nāo devem fazer, as situações de tensão produzem-se geralmente quando os enfermeiros detectam erros de prescrição terapêutica. Face às atitudes de desagrado tomadas pelos médicos quando são chamados à atenção sobre enganos, esquecimentos ou erros de prescrição, as atitudes tomadas pelos enfermeiros variam de acordo com a sua posiçăo na hierarquia de enfermagem e de acordo com a confiança que se tenha estabelecido entre médicos e enfermeiros num longo periodo de relações de trabalho."
}

Nas relações que são estabelecidas no contexto hospitalar vão aparecendo conflitos de ordem técnica e administrativa e o caminho tomado para resolvê-los é o da negociação. Neste sentido, a medida tomada quando do aparecimento do conflito, pela professora agredida com seus alunos de levar o problema para as instâncias de competência resolvê-los, buscou exatamente o caminho da negociação. Negociação esta que está em andamento até o presente momento, e seguiu todos os passos de encaminhamento possiveis, tanto na universidade, quanto na instituição hospitalar.

Sendo assim, na estrutura hospitalar da qual falamos, puderam ser identificadas diferentes formas de autoridade que se concentram, de forma variável, tanto no poder médico como no poder administrativo e as condições em que o poder médico se transmuta em poder administrativo e em que condições este poder incorpora dimensões do poder médico. Explicitando melhor, 
pode ser reconhecido no exercício do poder médico uma dimensão administrativa, assim como no exercício do poder administrativo uma dimensão do poder médico. Entretanto, nestas relações observamos que são transferidos mais poderes da dimensão médica do poder administrativo para o poder médico, do que da dimensão administrativa do poder médico para o poder administrativo. Segundo Focault (1995). "A partir do momento em que o hospital é concebido como um instrumento de cura e a distribuição do espaço torna-se um instrumento terapêutico, o médico passa a ser o principal responsável pela organização hospitalar".

Esta transmutação do poder médico em administrativo e este em poder médico ocorre no cotidiano da produção dos serviços hospitalares. No caso abordado neste trabalho ficou evidente o poder administrativo transferido ao médico ao iniciarmos o processo de negociação face ao conflito instalado. Segundo relato da enfermeira chefe do hospital, no momento em que a mesma levou o problema ao diretor clínico a fim de estabelecer um processo de negociação o mesmo conferiu toda autoridade do médico frente às questões administrativas. As palavras do diretor à enfermeira foram: "Se o médico falou, está falado. Nem o presidente da república tem autoridade para desfazer aquilo que o médico falou". Em relação ao caso relatado, se o médico não permitir que alunos de enfermagem façam seus estágios supervisionados em determinada unidade, a neonatologia, ninguém mais poderá afirmar o contrário.

Assim como ao médico é transferido o poder administrativo, aos docentes e alunos cabe ficar à margem de decisões tomadas em esferas superiores, enquanto atividade complementar ao ato médico. É importante ressaltar que este processo decisório está sendo permeado por um momento de transição na esfera administrativa da instituição citada por ter sido destituída, por intervenção do Estado, do poder gestor que vigorava quando se deu o conflito. Atualmente, o Estado mantém o poder administrativo e a mudança deu-se em função de outros conflitos que permeavam as relações naquele momento.

Com estas mudanças administrativas, direciona-se um novo enfoque ao relacionamento inter-institucional, ao ser solicitado à universidade um convênio de parceria para criação e implantação de uma diretoria do serviço de enfermagem, com administração de um docente do departamento de enfermagem. Apesar da ótica das relações ter se modificado, a negociação em relação ao campo de estágio em neonatologia permanece inalterada tendo se passado 2 anos do conflito inicial.

\section{A BUSCA DE UM "NOVO" AGIR COLETIVO: A (RE)CONSTRUÇÃO DAS AÇÕES DO COTIDIANO}

As relações de trabalho conflituosas, competitivas e alienantes no setor saúde podem ser explicadas não como desvio a ser tratado com medidas administrativas, mas sim como inerente ao processo de alienação do trabalhador no controle sobre seu processo de trabalho. Portanto, qualquer mudança que se pretenda realizar, levando em consideração a satisfação no trabalho e a recuperação da capacidade criativa da pessoa, é preciso que se tenha a coragem de superar os interesses corporativos e a lógica da organização capitalista do trabalho como forma de devolver ao homem a sua integridade (Pires, 1991).

Foucault (1991) analisa historicamente o poder enquanto instrumento capaz de explicar a produção dos saberes. O poder é entendido como estratégia, como relação de forças disseminadas e presente em todas as relações, em qualquer processo na forma de um sistema de dominação já estabelecido. Nesta perspectiva, a possibilidade de resistência, de contrapoder, encontra-se presente em toda a trama ou rede de poder, como pontos de resistência indefinidos, dinâmicos, variáveis, passiveis de desencadear rupturas nas diferentes relações sociais.

Um conflito de ordem técnica assume dimensões administrativas assim como o poder exercido pelo médico, confirmando-se a compatibilidade entre poder médico e poder jurídico- 
administrativo. De fato, em determinadas áreas de atividade hospitalar o poder médico goza de uma legalidade equivalente ao poder administrativo. Do que temos observado empiricamente percebemos que quanto mais complexo o serviço há exigência de maior competência técnicocientífica por parte do profissional que detém o poder nuclear na produção dos serviços hospitalares transferindo-Ihe autoridade técnica e administrativa. Para suas atitudes não é permitido nenhuma margem de questionamento, nem mesmo por parte da administração do hospital, ainda que o médico seja somente um prestador de serviços ou atue como contratado na instituição por tratar-se de um hospital público.

Os espaços de conflito exigem constantes processos de negociações nas relações cotidianas que nem sempre são estabelecidos de imediato, mas faz-se necessária a compreensão, reflexão e (re)construção permanente das ações e relações.

Temos observado que as formas do poder médico medeiam a análise das áreas amplas de influência de que dispõem os médicos no exercício de uma autoridade e responsabilidade a partir das quais se definem a extensão e os limites da autoridade e responsabilidade dos demais profissionais da equipe de saúde que atuam no ambiente hospitalar. Os médicos da unidade, em suas atividades cotidianas, instauram constantemente regras implícitas e normas informais de funcionamento estabelecendo-se, para os demais profissionais, relações permanentemente inseguras e equivocadas com as regras e normas hospitalares, quando pressionados a cumprir simultaneamente umas e outras.

Como não há incompatibilidade explicita entre as regras das quais falamos, pode haver, em determinadas situaçōes, incompatibilidade entre interesses especificos produzindo situações de conflito cuja resolução passa pela cumplicidade de interesses ou, quando há divergência de interesses, passa pela negociação através da troca de favores, cedência de algumas parcelas do poder de decisão ou invasão reciproca de territórios e funções.

Os médicos dispõem do saber de diagnosticar e tratar, são eles que estabelecem formalmente o processo de internamento e, portanto, sentem-se poderosos frente aos corpos biológicos doentes e sua posição hierárquica no ambiente hospitalar resulta numa autoridade científica indiscutivel. Os demais profissionais que atuam no processo de cura não participam na escolha da terapêutica adequada a cada caso clínico. Assim, a aceitação do exercício da autoridade do médico toma a forma de um implícito contrato científico e social entre os pares de um mesmo corpo profissional cujos termos se definem e justificam na base da diferenciação das competências e da qualidade dos saberes entre médicos.

As situações de tensão giram em torno dos problemas resultantes de perturbações das fronteiras que demarcam os territórios e funções dos profissionais, espaços permitidos e proibidos a enfermeiros. Criam-se zonas de indeterminação e ambigüidade em que serão negociados os saberes, porém, conservando intacta a relação de poder, um poder disciplinar.

\footnotetext{
ABSTRACT: The purpose of this article is to make a critical analysis about power relationships, which permeate daily professional and /or institutional actions in the hospital environment. This reflection is based on a concrete situation experienced by a group of nursing professors from a state university in Paraná, which unleashed conflicts concerning interprofessional and interinstitutional power relationships. This study focuses on power relationships in the hospital emphasizing the interrelations that characterize nursing practice. We believe that these relationships can only be understood, reflected upon and rebuilt in the context of daily practice, as new ways of collective action are sought.
}

KEYWORDS: power, interprofessional and interinstitutional relationships 
RESUMEN: El estudio tiene por objetivo hacer una reflexión crítica sobre las relaciones de poder que perpasan las acciones profesionales o institucionales en la vida cotidiano del ambiente hospitalar. Se toma como base una situación concreta vivida por un grupo de enfermeros docentes de una universidad pública estadual del interior del Estado de Paraná que desencadenó un proceso conflictivo en las relaciones de poder (inter)profesionales e (inter)institucionales. Reflexiona sobre la relación de poder en el hospital y destaca las interrelaciones que caracterizan la práctica de enfermeria. Creemos que estas relaciones sólo se pueden comprender, analizar y (re)construir en lo cotidiano de las acciones y en la búsqueda de un "nuevo" proceder colectivo.

PALABRAS CLAVE: poder, relaciones (inter)profesionales e (inter)institucionales

\section{REFERÊNCIAS BIBLIOGRÁFICAS}

AGUDELO, M.C.C. Características generales del trabajo en salud. In: MACHADO, M.H. Profissöes de saúde : uma abordagem sociológica. Rio de Janeiro : Fiocruz, 1995.

CARAPINHEIRO, G. Saberes e poderes no hospital. Lisboa-Portugal, 1993.

FOUCAULT, M. Vigiar e punir. 8.ed. Petrópolis: Vozes, 1991.

Microfísica do poder. Rio de Janeiro : Graal, 1995.

PIRES, D.P. Hegemonia médica na saúde e a enfermagem. São Paulo: Cortez, 1989.

Recebido em agosto de 1998

Aprovado em outubro de 2000 